\title{
Analysis of Muscle Activity During Shooting Motion of Korean Traditional Archers
}

\author{
Changsun Kim¹, Zhou YueZhu', Dong-Ho Park², Kihoon Kim³, Wangsoo Jeong ${ }^{3}$, \\ Hye-ree Kim, Kikwang Lee ${ }^{5}$, \& Seok-Ki Min ${ }^{6}$ \\ ${ }^{1}$ Department of Physical Education, Dongduk Women's University, Seoul, Korea \\ ${ }^{2}$ Program in Biomedical Science \& Engineering, Department of Kinesiology, Department of Biomedical Science, \\ Inha University, Incheon, Korea \\ ${ }^{3}$ Department of Military History, Korea Military Academy, Seoul, Korea \\ ${ }^{4}$ Department of Physical Education, Graduate School, Kookmin University, Seoul, Korea \\ ${ }^{5}$ Department of Sports and Health Rehabilitation, Kookmin University, Seoul, Korea \\ ${ }^{6}$ Korea Institute of Sport Science, Seoul, Korea
}

\begin{abstract}
[Abstract] The past few decades has seen increasing kinematic studies using surface electoromyography (EMG) in archery, however there has been no such specific study in Korean traditional archery. The purpose of this study was to evaluate EMGs during archery shooting motion in Korean traditional archers. Ten men Korean traditional archers were participated, and divided into two groups according to the shooting stance; parallel stance group(PSG, $n=5$ ) and oblique stance group(OSG, $n=5)$. The surface EMGs were measured 12 muscles during shooting motion of five events including Junbi(Set), Geogung(Set up), Manjak(Full draw), Balsi(Release), Machigi(Ending). At the result, muscle activity of posterior deltoid, trapezius, rhomboid major, latissimus dorsi, biceps brachii, forearm extensor bundle, triceps brachii, levator scapulae significantly increased at event of full draw and release, then significantly decreased again at event of ending, respectively $(\mathrm{p}<.01, \mathrm{p}<.001)$. The muscle activity of erector spinae(ES) was also significantly increased at event of full draw and release( $<<.01, \mathrm{p}<.001)$, while no significant changes in muscles of rectus abdominis, rectus femoris(RF), gluteus maximus. As a result of comparing PSG and OSG, muscle activity of RF in OSG was higher than PSG at event of release $(\mathrm{p}<.05)$, it remained until event of ending $(\mathrm{p}<.05)$. On the other hand, the higher the tension of the bow, the higher the muscle activity of the draw arm at event of release( $\mathrm{p}<.05)$. These results suggest that when Korean traditional archery shooting, both side arm and back muscles are more activated than the abdomen, leg and hip muscles. The parallel stance might suppress the muscle activity of the lower extremities to twist the upper body. And the higher bowstring tension needs to increase of muscle strength in $\mathrm{BB}$ of draw arm.
\end{abstract}

Key words: Korean traditional archery, body weight movement, shooting time, joint muscle strength, postural stability.

논문 투고일 : 2021.02.09.

논문 수정일 : 2021.03.12.

게재 확정일 : 2021.03.17.

* 교신저자 : 민석기(minseokki@kspo.or.kr)

\author{
서 론 \\ 활쏘기는 정적인 스포츠로(Kim, 2000), 자신감이나 집중 \\ 력 등 심리 상태(Kim, Kim \& So, 2015) 뿐만 아니라 근육의
}


균형 유지(Park \& Han, 2019a) 및 좌우 팔 힘의 분배 (McGuine, 2006), 슈팅 시 동작의 일관성(Kim \& Kim, 2005)과 자세의 안정성 및 무게중심(Kim, Kim, \& An. 2015; Kim, 2008; An, 2018) 등 다양한 요인들이 영향을 미 친다. 특히 활쏘기 동작에서의 활을 잡고 미는 동작과 화살과 시위를 잡고 당기는 동작(Leroyer, Hoecke \& Helal, 1993) 을 담당하는 각 부위의 근육 작용은 미세하게 조절되고 제어 된다(Manson \& Pelgrim, 1986). 최근 양궁 기술에 대한 연 구에서는 드로잉에서 릴리즈까지의 슈팅 동작을 경기력과 관 련된 핵심 기술로 보고, 슈팅 동작 시의 근육의 미세한 조절과 제어 작용을 밝히기 위하여 근전도(electromyography, $\mathrm{EMG}$ )를 이용하여 근활성도를 분석하고 있다(Soylu, Ertan, \& Korkusuz, 2006; Ertan, 2008; Park \& Han, 2019a, Choi, 2020a; Choi, 2020b).

근활성도는 주로 팔과 어깨, 몸통 등으로 나누어 분석되 고 있다. Ertan 등(2003) 은 슈팅 시 양궁 활쏘기 시의 아래 팔(forearm)의 얕은손가락굽힘근(Flexor digitorum superficialis)과 손가락폄근(Extensor digitorum)의 근 활성을 검토하였고, 또 다른 연구에서 당기는 팔의 훅킹 (hocking) 기술에 관여하는 팔 근육의 활성도를 검토 하고 있다(Soylu, Ertan, \& Korkusuz, 2006). 또한, Park \& $\mathrm{Han}(2019 \mathrm{a})$ 과 Kim 등(2018), Kim \& Park(2009)은 활 의 방향성을 결정하는 어깨 근육의 근 활성도를 검토하고 있 으며, 적절한 슈팅 기술을 달성하기 위해 어깨 관절의 안정 화 위한 근육 활성이 이루어져야 한다고 밝히고 있다 (Simsek \& Ertan, 2014). Lee, Seo \& Jeong(2019)과 Park \& Han(2019b)은 양궁 활쏘기 동작 시의 몸통의 안정 화와 관련된 근활성을 검토하고 있으며, 릴리즈구간에서의 흔들림 없이 안정성을 유지 할 수 있는 어깨 안정화 훈련프 로그램이 필요하다고 주장하고 있다. 양궁의 활쏘기 동작은 스탠스(stance), 세트(set), 셋업(set-up), 드로잉(drawing), 풀 드로우(full draw), 릴리즈(relaese), 팔로스로우 (follow throw)로 구분된다(Park \& Han, 2019b). 활쏘기 동작은 약 10초 15초 내외의 짧은 시간에 이루어지며, 각 동작이 구분되기 보다는 물 흐르듯이 자연스럽게 연속적으 로 이루어진다. 따라서 발에서부터 엉덩이, 몸통, 어깨, 팔, 손으로 이어지는 유기적인 동작에 의하여 활쏘기가 이루어 지는 것이다. 이러한 관점에서 한정된 국소 부위 보다는 전 신의 근 활성을 검토하여 근육 작용을 이해하는 것이 중요하 다고 하겠다. 최근 Choi(2020a)의 연구에서는 Case
Study로 여자 중학교 양궁 선수 한명의 좌우 팔 각각 4 개의 근육과 척주기립근 좌우 2 개의 총 10 개 근육의 활성을 검토 하였다. 또한 중고 여자 양궁선수 9명에게도 동일하게 상지 주요 근육과 척추기립근의 근활성도를 비교하여 팔과 몸통 의 동시 작용을 검토하고 있다(Choi, 2020b). 그러나 발, 엉덩이, 몸통, 어깨, 등, 팔의 근활성 변화를 동시에 검토한 연구는 찾을 수 없다.

한편, 우리나라의 전통 활쏘기인 국궁은 서양식 활쏘기 인 양궁과 구별된다. 국궁과 양궁 모두 큰 틀에서 활쏘기라 는 행위 자체는 같지만, 활과 화살의 재료, 형태, 크기뿐만 아니라, 사거리, 그립, 활쏘기 방법 등 많은 부분이 다르다. 따라서 국궁 활쏘기 동작에 대한 운동학적 분석이 필요하나 국궁 궁사의 근력의 특성을 일반인과 비교한 연구(Kim 등, 2017)와 활쏘기 동작 시의 체중이동과 수행 속도를 검토한 연구(Kim, 2020)가 있을 뿐 운동학적 연구는 미비한 실정 이다. 국궁 활쏘기 동작도 양궁과 마찬가지로 발디딤, 살메 기기, 몸가짐(Set), 거궁(Set up), 만작(Full draw), 발시 (Release), 마치기(Ending)로 구분할 수 있다. 특히, 거궁 에서 발시까지의 동작은 장전한 활을 들어올려 밀고 당겨 조 준을 하여 활을 쏘는 동작으로, 양궁의 드로잉에서 릴리즈 까지의 동작에 해당되어 마찬가지로 핵심 동작으로 평가되 고 있으나, 국궁 활쏘기 동작에 대한 근활성을 검토한 연구 는 전무한 실정이다.

국궁의 입사 자세(Shooting stance)는 양궁과 달리 과 녁과 마주 보고 서는 마주 서기(parallel stance)와 과녁에 비스듬히 서는 사선 서기(oblique stance)가 있다. 마주 서 기는 전통의 활쏘기 자세이며 조준을 오래 하는 지사가 가능 하다고 주장(Kim, 2020)되는 반면, 사선 서기의 경우 과녁 에 대항하여 애초에 비스듬히 서는 자세로, 안정적이라 주 장되고 있다. 이 두 자세로 활쏘기 시의 근활성을 비교하는 것도 의의가 있을 것이다.

따라서 본 연구에서는 숙련된 남성 국궁 궁사를 대상으로 활쏘기 동작 시의 양쪽 팔과 등, 어깨, 몸통, 다리, 엉덩이에 작용하는 총 12 개 근육의 근전도를 분석하고, 실제 동작이 일어나는 몸가짐에서부터, 거궁, 만작, 발시, 마치기 시의 근활성을 분석하였다. 우리나라 전통 활쏘기인 국궁은 지난 해 국가무형문화재 제 142 호로 지정되었으며, 유네스코 인 류무형문화유산 등재를 추진하고 있다. 본 연구는 세계화를 앞둔 우리나라의 활쏘기에 대한 과학적이고 객관적인 기초 자료를 제공하는 것에 목적을 두었다. 


\section{연구방법}

\section{연구대상}

국궁 활쏘기 동작 시 근활성 분석을 위하여 평균 연령 약 $49.4 \pm 8.8$ 세의 남성 국궁 선수 10 명을 모집하였으며, 활쏘 기 서는 자세에 따라 마주서기 집단(parallel stance group, PSG, $\mathrm{n}=5$ )과 사선서기 집단(oblique stance group, OSG, n=5)으로 나누었다(Table 1). 이들은 활쏘기 동작의 수행속도를 분석한 연구와 동일한 대상자로(Kim, 2020), 평소대로 가장 편안한 자세로 활쏘기를 수행하도록 한 후 두 집단으로 구분하였다. 이들 중 1 명이 왼손잡이였으며, 좌우 차이 통일을 위하여 활쏘기 동작과 전극부착 부위는 다른 오 른손잡이와 대칭이 되게, 오른손잡이의 오른손과 왼손잡이 의 왼손을 주동팔(dominant arm)로 설정하여 측정하였 다. 실험에 미치는 영향을 최소화하기 위하여 실험 전 48시 간 동안 심한 운동을 금지 시켰다. 사전에 대상자들에게 D 대학교의 실험에 대한 규정에 따라 실험내용 및 피해점, 실험 중지의 자유 등에 대하여 자세히 설명하였고 동의를 얻었다.

\section{측정방법}

\section{1. 사용 장비 및 실험 절차}

활쏘기 측정은 안전장치가 완비된 $\mathrm{K}$ 대학교의 Biomechanics 실험실에서 진행되었다. 활과 화살은 각 대상자의 장비를

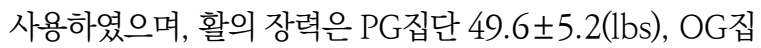
단 51.0 $\pm 6.5(\mathrm{lbs})$ 로 두 집단 간의 차이는 없었다. 실험용 꽂힘 과녁(고침)은 사대로부터 $5 \mathrm{~m}$ 거리에 설치하였으며, 실 제 측정에 앞서 전신 준비운동과 활쏘기 연습을 충분히 실시 하였다. 활쏘기 수행 순서는 무작위로 결정하였고, 가능한
실제 습사 및 경기에서 수행하는 것과 동일하게 수행 하도록 하였다.

\section{2. 근활성 분석}

활쏘기 동작의 근활성 분석을 위하여 무선 방식의 근전도 측정 장치(Delsys wireless EMG, USA)를 이용하였다. 표면 전극 부착위치는 Seniam (2006)의 방법을 참고로 총 12 개 의 채널을 사용하여 주로 사용되는 근육들 중 어깨와 등을 포 함한 깍지팔(Draw arm) 5곳, 줌팔(Bow arm) 3곳, 몸통 (Trunk) 2곳, 다리(Leg)와 엉덩이(Gluteus) 각각 1 곳의 근 육의 힘살(belly)에 전극을 부착하였다(Fig. 1). 전극의 탈락 을 방지하기 위해 kinesio tape를 무선 전극 위에 부착하였 다. 근전도 측정을 위한 Sampling rate는 $1800 \mathrm{~Hz}$ 로 설정 하여 Band pass filtering을 하였다. 측정된 근전도 신호는 RMS(root mean square)처리 하여 정량화 하였으며, 사전 에 측정한 각 근육의 최대수의적수축(maximum voluntary contraction: MVC)을 기준값으로 표준화(\%MVC)하였다 (Kim \& Youm, 2013). 사용된 식은 다음과 같다.

$$
\begin{aligned}
& \text { 표준화 근전도 }(\% \mathrm{MVC})=(\text { 측정된 근전도 값 } \div \\
&\text { 최대수의적수축 근전도 값 }) \times 100 .
\end{aligned}
$$

\section{3. 분석 동작(Event) 및 국면(Phase) 설정}

활쏘기 동작 시의 근활성 분석을 위하여 활쏘기 주요 동 작(Event, Ev) 5 개 및 동작과 동작 사이의 4 개의 국면 (Phase)으로 설정하였다(Fig. 2). Ev(1)은 준비(Set) 동작, $\mathrm{Ev}$ (2)는 거궁(Set up) 동작, Ev(3)은 만작(Full draw) 동작, $\mathrm{Ev}$ (4)는 발시(Release) 동작, $\mathrm{Ev}$ (5)는 마치는(Ending) 동작 이다. $\mathrm{Ph}(1)$ 은 $\mathrm{Ev}(1) \mathrm{Ev}(2)$ 의 준비 자세에서 활을 머리 위로

Table 1 . The physical characteristics of participants

\begin{tabular}{rccccc}
\hline \hline & All(n=10) & PSG(n=5) & OSG(n=5) & t & p \\
\hline Age(yrs) & $49.4 \pm 8.8$ & $52.6 \pm 6.9$ & $50.0 \pm 10.0$ & -0.479 & .645 \\
Weight(kg) & $74.2 \pm 6.8$ & $72.8 \pm 7.0$ & $75.5 \pm 7.2$ & -0.023 & .987 \\
Height(cm) & $169.6 \pm 3.5$ & $169.6 \pm 2.5$ & $16.9 .6 \pm 4.6$ & 0.584 & .563 \\
Bowstring tension(lbs) & $50.7 \pm 5.8$ & $49.6 \pm 5.2$ & $51.0 \pm 6.5$ & 0.376 & .717 \\
Average hit rate(hits/45 shoot) & $33.0 \pm 5.7$ & $34.6 \pm 6.5$ & $31.4 \pm 4.8$ & 0.338 & .746 \\
Training experience(months) & $89.6 \pm 63.8$ & $111.6 \pm 77.6$ & $62.6 \pm 36.4$ & -1.409 & .197 \\
\hline \hline
\end{tabular}

Values are Mean \pm SD. PSG, parallel stance group; OSG, oblique stance group. No significant difference found between PSG and OSG by independent t-test, 


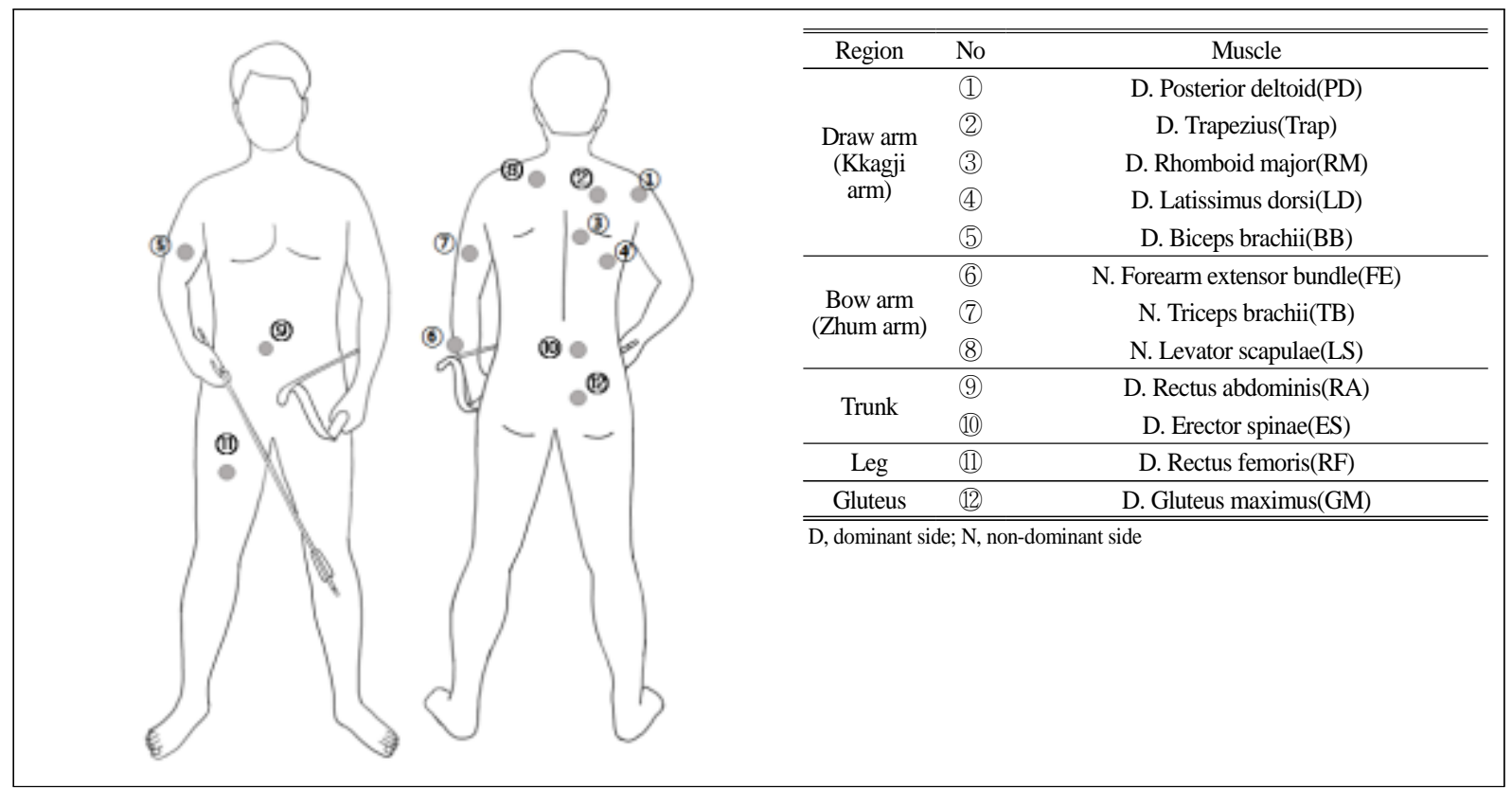

Fig. 1. Attachment positions of surface electrodes

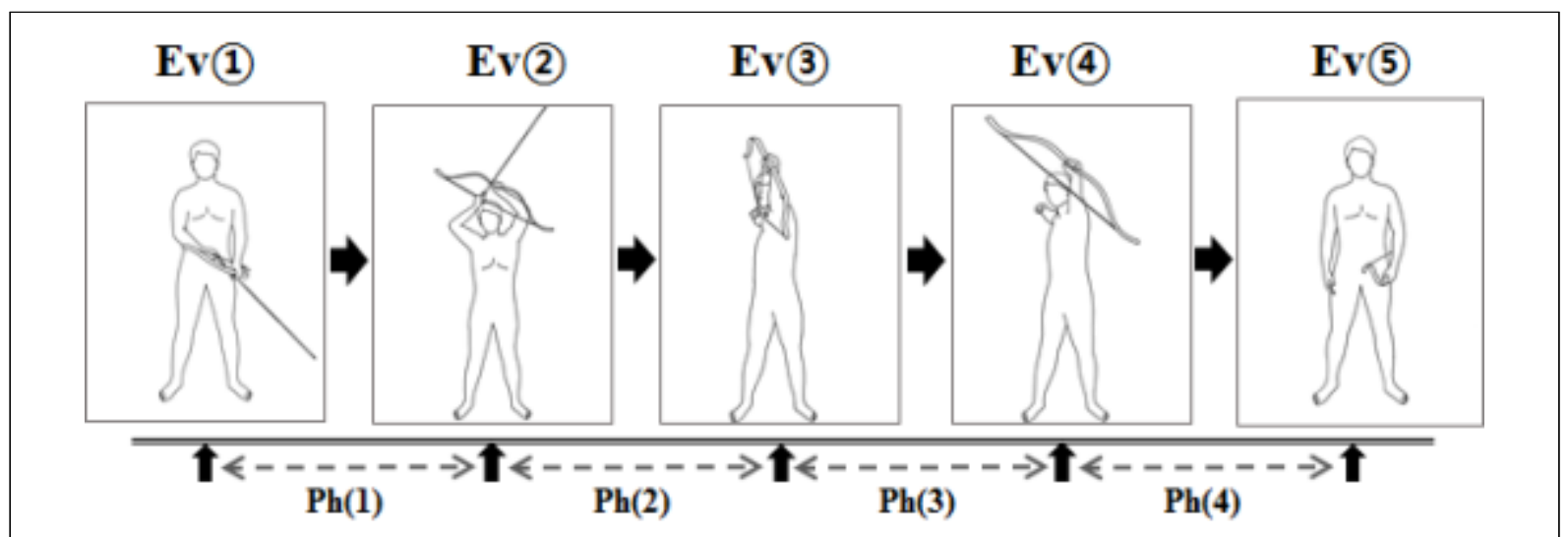

Fig. 2. The event and phase classification during shooting motion in Korean traditional archers. Ev(1), Junbi(Set); Ev(2), Geogung(Set up); Ev(3), Manjak(Full draw); Ev(4), Balsi(Release); Ev(5), Machigi(Ending); Ph(1), phase of Deuleo oligi(E (1) E(2); $\mathrm{Ph}(2)$, phase of Milgo danggigi(E(2) E(3); $\mathrm{Ph}(3)$, phase of Guchigi(E(3) E(4); $\mathrm{Ph}(4)$, phase of Mamuri(E(4) E(5)).

들어 올리는(들어 올리기) 국면이다. $\mathrm{Ph}(2)$ 는 $\mathrm{Ev}$ (2) $\mathrm{Ev}$ (3)의 활을 밀고 당기면서 끝까지 당기는(밀고 당기기) 국면이다. $\mathrm{Ph}(3)$ 는 $\mathrm{Ev}(3) \mathrm{Ev}(4)$ 의 가득 당겨서 조준을 하는(군히기) 국 면이다. $\mathrm{Ph}(4)$ 는 $\mathrm{Ev}(4) \sim \mathrm{Ev}(5)$ 의 발시를 마치고 준비자세로 돌아오는(마무리) 국면이다.

\section{자료처리방법}

본 연구는 비확률적(nonprobability) 판단표집(judgement sampling)방법으로 연구대상를 구분하여 자료를 분석하였 다. 자료처리는 SPSS for window(ver. 24.0)를 이용하였 다. 전체 대상자의 평균과 표준편차를 산출하였으며, 활쏘 기 서는 자세에 따른 집단의 차이 검증은 독립 T-test를 사 
용하였다. 활쏘기 동작의 5 개 동작에 따른 각 평균의 차이는 일원분산분석(one-way ANOVA)에 의한 다중비교를 실시 하였으며, ANOVA 검사에서 유의한 차이가 있을 경우, $\mathrm{LSD}$ 를 통해 사후검사를 실시하였다. 모든 통계치의 유의수 준은 5\% (p<.05) 이하로 설정하였다.

\section{연구결과}

\section{활쏘기 동작 시의 팔, 다리, 몸통 근육의 근활성(EMGs) 변화}

연구 대상자 한 사람의 각 근육에서의 활쏘기 동작 시의 근활성(\%MVC) 변화를 〈Fig. 3〉에 나타냈다. 활쏘기 동작 은 E(1) 준비(Set)부터 E(5) 마무리(Ending)까지를 100\%으로

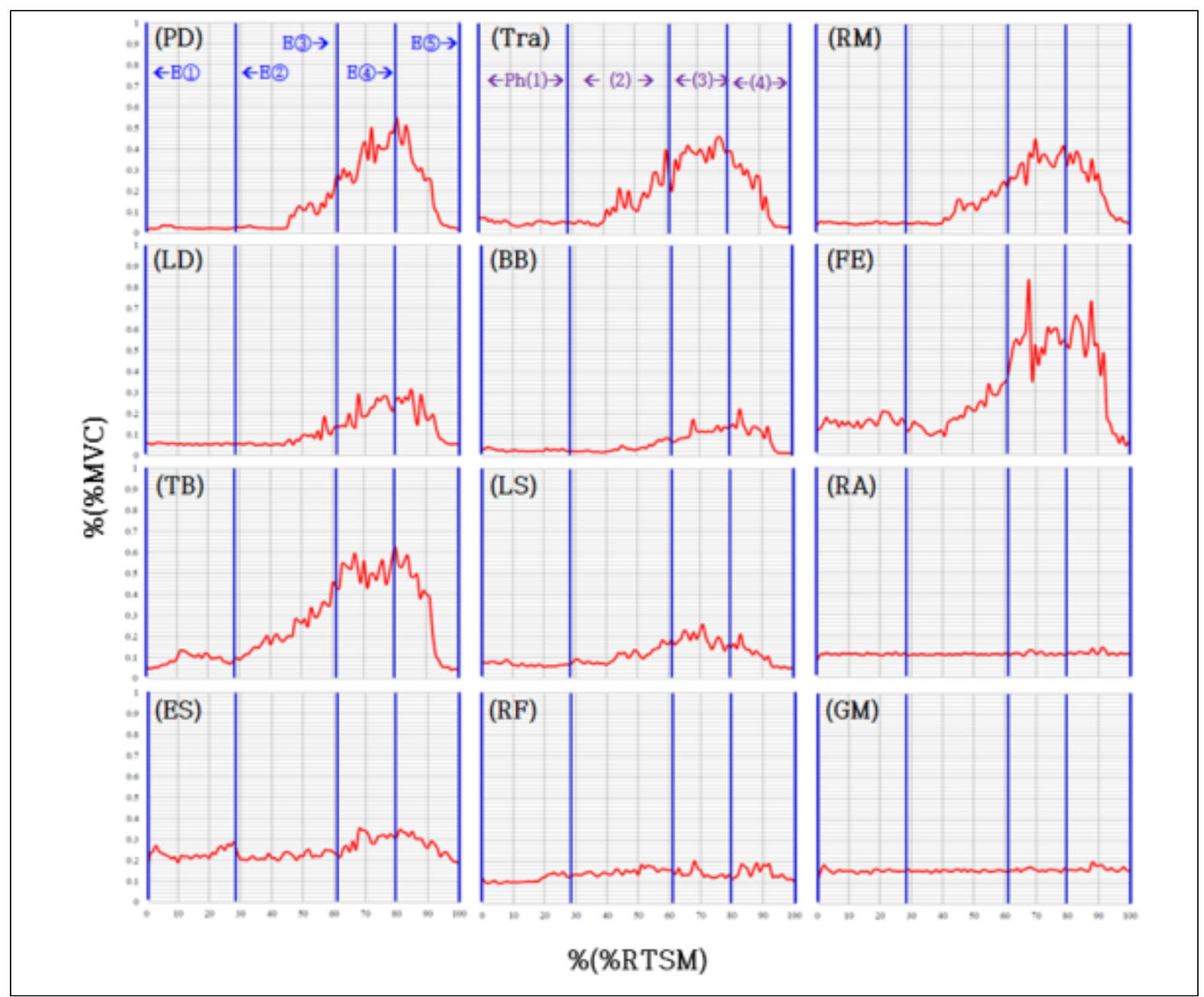

Fig. 3. The sample diagram of a subject which change of muscle activity(EMGs) during shooting motion in Korean traditional archers. \%MVC, \% Maximum voluntary contraction; \%RTSM, \% Relation time of shooting motion; PD, Posterior deltoid; Tra, Trapezius; RM, Rhomboid major; LD, Latissimus dorsi; BB, Biceps brachii; FE, Forearm extensor bundle; TB, Triceps brachii; LS, Levator scapulae, RA, Rectus abdominis, ES, Erector spinae; RF, Rectus femoris; GM, Gluteus maximus; E(1), Junbi(Set); E(2), Geogung(Set up); E(3), Manjak(Full draw); E(4), Balsi(Release); E(5), Mamuri(Ending); $\mathrm{Ph}(1)$, phase of Deuleo oligi(E(1) E(2); $\mathrm{Ph}(2)$, phase of Milgo danggigi(E(2) E(3); $\mathrm{Ph}(3)$, phase of Guchigi(E(3) E(4)); $\mathrm{Ph}(4)$, phase of Mamuri(E(4) E(5)). 
하여 표준화하였다(\% Relation time of shooting motion, RTSM). 양팔의 근육들을 보면 $\mathrm{Ph}(1)$ 인 들어 올리기 국면에 서는 대부분의 근육의 활성에 큰 변화는 없었지만, $\mathrm{Ph}(2)$ 인 밀고 당기기 국면에서 점차 근활성이 증가하고 $\mathrm{Ph}(3)$ 인 굳 히기 국면에서 최대치를 나타내다 $\mathrm{Ph}(4)$ 인 마무리 국면에 서 원래의 근활성으로 돌아오는 형태를 나타냈다. 몸통과 엉덩이, 다리 근육에 있어서는 국면별 변화는 크지 않은 것 으로 나타났다.

〈Table 2〉에는 전체 대상자의 활쏘기 동작 시의 각 근육에서의 평균 근활성 변화를 나타냈다. 깍지팔(Draw arm)의 뒤어깨세모근(Posterior deltoid, PD)과 등세모 근(Trapezius, Trap), 큰마름근(Rhomboid major, $\mathrm{RM}$ ), 넓은등근(Latissimus dorsi, $\mathrm{LD}$ ), 위팔두갈래근 (Biceps brachii, BB)과 줌팔(Bow arm)의 아래팔폄 근무리(Forearm extensor bundle, $\mathrm{FE}$ )와 위팔세갈래 근(Triceps brachii, TB), 어깨올림근(Levator scapulae, LS)에서 유의한 차이가 나타났다(p<.001). 사후 검정 결과 $\mathrm{Ev}$ (1)의 준비(Set)와 Ev(2)의 거궁(Set up)에 비교하여 Ev(3)
만작(Full draw)과 Ev(4) 발시(Release)에 유의하게 증가하 였다가(p<.001), Ev(5) 마치기(Ending)에 유의하게 다시 감 소하였다(p<.001). Ev(3)과 Ev(4)에서의 유의한 차이는 나타 나지 않았다. 몸통(Trunk)에 있어서는 배곧은근(Rectus abdominis, RA)에서는 유의한 차이는 나타나지 않았지만, 척주세움근(Erector spinae, ES)에 있어서는 유의한 차이 가 나타났다(p<.027). 사후 검정 결과 $\mathrm{Ev}(1)$ 의 준비(Set)에 비교하여 Ev(3) 만작과 Ev(4) 발시에 유의하게 증가하였다가 (p<.01), Ev5) 마치기(Ending)에 유의하게 다시 감소하였 다(p<.01), 넙다리곧은근(Rectus femoris, RF)과 큰볼기 근(Gluteus maximus, $\mathrm{GM}$ )에 있어서는 활쏘기 동작 시의 유의미한 변화는 나타나지 않았다.

\section{활쏘기 서는 자세에 따른 팔, 다리, 몸통 근육의 근활성 (EMGs)의 변화}

〈Table 3〉에는 마주 서기 집단(PSG)과 사선 서기 집단 (OSG)으로 나누어 활쏘기 동작 시의 각 근육에서의 평균 근

Table 2. The change of muscle activity at each event during shooting motion in Korean traditional archers.

\begin{tabular}{|c|c|c|c|c|c|c|c|c|}
\hline \multicolumn{2}{|r|}{ Muscle } & & & & & & \multirow[t]{2}{*}{$f$} & \multirow[t]{2}{*}{$p$} \\
\hline & & Ev(1) & $\mathrm{Ev}(2)$ & $\mathrm{Ev}(3)$ & $\mathrm{Ev}(4)$ & Ev(5) & & \\
\hline \multirow{5}{*}{ Draw arm } & PD & $3.4 \pm 1.8$ & $8.7 \pm 6.0$ & $50.9 \pm 19.8^{\mathrm{a}, \mathrm{b}}$ & $42.1 \pm 11.7^{\mathrm{a}, \mathrm{b}}$ & $2.0 \pm 0.5^{\mathrm{c}, \mathrm{d}}$ & 47.578 & .000 \\
\hline & Tra & $8.9 \pm 2.6$ & $18.8 \pm 21.1$ & $58.6 \pm 29.7^{\mathrm{a}, \mathrm{b}}$ & $55.4 \pm 25.6^{\mathrm{a}, \mathrm{b}}$ & $4.7 \pm 1.7^{\mathrm{c}, \mathrm{d}}$ & 15.123 & .000 \\
\hline & $\mathrm{RM}$ & $7.3 \pm 4.8$ & $19.9 \pm 19.6$ & $57.9 \pm 40.3^{\mathrm{a}, \mathrm{b}^{\prime}}$ & $55.8 \pm 31.2^{\mathrm{a}, \mathrm{b}^{\prime}}$ & $6.3 \pm 5.0^{\mathrm{c}, \mathrm{d}}$ & 7.820 & .000 \\
\hline & LD & $6.1 \pm 1.4$ & $7.9 \pm 2.9$ & $26.6 \pm 12.6^{\mathrm{a}, \mathrm{b}}$ & $25.8 \pm 8.9^{\mathrm{a}, \mathrm{b}}$ & $5.5 \pm 1.2^{\mathrm{c,d}}$ & 23.538 & .000 \\
\hline & $\mathrm{BB}$ & $3.3 \pm 1.3$ & $4.8 \pm 4.5$ & $15.9 \pm 7.0^{\mathrm{a}, \mathrm{b}}$ & $16.2 \pm 6.9^{\mathrm{a}, \mathrm{b}}$ & $1.9 \pm 0.6^{\mathrm{c,d}}$ & 18.705 & .000 \\
\hline \multirow{3}{*}{ Bow arm } & $\mathrm{FE}$ & $13.1 \pm 8.6$ & $17.1 \pm 8.3$ & $41.1 \pm 21.7^{\mathrm{a}, \mathrm{b}^{\prime}}$ & $45.2 \pm 20.8^{\mathrm{a}, \mathrm{b}}$ & $3.9 \pm 1.4^{\mathrm{c,d}}$ & 15.617 & .000 \\
\hline & TB & $5.8 \pm 3.5$ & $14.4 \pm 12.5$ & $58.8 \pm 24.3^{\mathrm{a}, \mathrm{b}}$ & $56.1 \pm 21.1^{\mathrm{a}, \mathrm{b}}$ & $4.1 \pm 2.2^{\mathrm{c,d}}$ & 30.844 & .000 \\
\hline & LS & $8.3 \pm 2.9$ & $13.2 \pm 7.6$ & $30.9 \pm 12.4^{\mathrm{a}, \mathrm{b}}$ & $31.2 \pm 13.7^{\mathrm{a}, \mathrm{b}}$ & $6.7 \pm 3.7^{\mathrm{c,d}}$ & 17.368 & .000 \\
\hline \multirow{2}{*}{ Trun } & RA & $7.1 \pm 5.7$ & $8.3 \pm 6.4$ & $10.8 \pm 11.3$ & $8.6 \pm 5.0$ & $7.9 \pm 5.1$ & .334 & .853 \\
\hline & ES & $9.0 \pm 4.0$ & $12.9 \pm 7.7$ & $17.6 \pm 8.9^{\mathrm{a}^{\prime}}$ & $18.9 \pm 9.8^{\mathrm{a}^{\prime}}$ & $9.9 \pm 6.1^{\mathrm{c}^{\prime}, \mathrm{d}^{\prime}}$ & 3.081 & .027 \\
\hline Leg & $\mathrm{RF}$ & $8.2 \pm 4.3$ & $10.5 \pm 4.2$ & $11.7 \pm 7.3$ & $10.7 \pm 4.7$ & $7.9 \pm 3.2$ & 1.138 & .351 \\
\hline Glut & GM & $14.0 \pm 5.4$ & $15.6 \pm 8.7$ & $13.6 \pm 5.3$ & $13.5 \pm 5.4$ & $12.1 \pm 6.2$ & .391 & .814 \\
\hline
\end{tabular}

Values are expressed as the mean \pm SD. Trun, Trunk; Glut, Gluteus; PD, Posterior deltoid; Tra, Trapezius; RM, Rhomboid major; LD, Latissimus dorsi; BB, Biceps brachii; FE, Forearm extensor bundle; TB, Triceps brachii; LS, Levator scapulae, RA, Rectus abdominis, ES, Erector spinae; RF, Rectus femoris; GM,

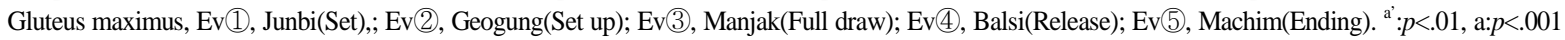
significant difference vs Ev(1); ${ }^{\mathrm{b}^{\prime}}: p<.01,{ }^{\mathrm{b}}: p<.001$ significant difference vs Ev(2); ${ }^{\mathrm{c}^{\prime}}: p<.01,{ }^{\mathrm{c}}: p<.001$ significant difference vs Ev(3); ${ }^{\mathrm{d}}: p<.01,{ }^{\mathrm{d}}: \mathrm{p}<.001$ significant difference vs Ev(4). 
Table 3. The comparison of muscle activity at each event between parallel and oblique stance group during shooting motion in Korean traditional archers.

(unit : \%MVC)

\begin{tabular}{|c|c|c|c|c|c|c|c|}
\hline & \multirow[t]{2}{*}{ Muscle } & \multirow[t]{2}{*}{ Group } & & & & & \\
\hline & & & Ev(1) & $\mathrm{Ev}(2)$ & Ev(3) & Ev(4) & Ev(5) \\
\hline \multirow{15}{*}{$\begin{array}{l}\text { Draw } \\
\text { arm }\end{array}$} & \multirow{3}{*}{ PD } & PSG & $2.8 \pm 0.8$ & $9.6 \pm 7.1$ & $54.2 \pm 26.2$ & $40.4 \pm 11.0$ & $1.8 \pm 0.4$ \\
\hline & & OSG & $4.0 \pm 2.3$ & $7.8 \pm 5.4$ & $47.6 \pm 13.1$ & $43.8 \pm 13.3$ & $2.2 \pm 0.4$ \\
\hline & & $t(\mathrm{p})$ & $-1.078(.313)$ & $0.453(.663)$ & $0.505(.627)$ & $-0.440(.672)$ & $-1.414(.195)$ \\
\hline & \multirow{3}{*}{ Tra } & PSG & $7.4 \pm 1.3^{*}$ & $22.6 \pm 28.0$ & $51.4 \pm 31.7$ & $49.0 \pm 26.9$ & $3.8 \pm 0.4$ \\
\hline & & OSG & $10.8 \pm 2.8$ & $14.0 \pm 9.3$ & $67.5 \pm 28.7$ & $63.5 \pm 24.9$ & $5.8 \pm 2.1$ \\
\hline & & $t(\mathrm{p})$ & $-2.414(.046)$ & $0.583(.578)$ & $-0.789(.456)$ & $-0.829(.435)$ & $-2.089(.075)$ \\
\hline & \multirow{3}{*}{$\mathrm{RM}$} & PSG & $5.3 \pm 3.0$ & $19.3 \pm 18.5$ & $39.8 \pm 23.9$ & $42.5 \pm 20.7$ & $3.5 \pm 1.7$ \\
\hline & & OSG & $9.0 \pm 5.7$ & $20.4 \pm 22.7$ & $72.4 \pm 47.2$ & $66.4 \pm 36.1$ & $8.6 \pm 5.7$ \\
\hline & & $t(\mathrm{p})$ & $-1.181(.276)$ & $-0.082(.937)$ & $-1.250(.251)$ & $-1.168(.281)$ & $-1.699(.133)$ \\
\hline & \multirow{3}{*}{ LD } & PSG & $6.6 \pm 1.9$ & $7.6 \pm 2.6$ & $28.6 \pm 15.8$ & $24.8 \pm 6.8$ & $5.0 \pm 1.0$ \\
\hline & & OSG & $5.6 \pm 0.5$ & $8.2 \pm 3.5$ & $24.6 \pm 9.8$ & $26.8 \pm 11.4$ & $6.0 \pm 1.2$ \\
\hline & & $t(\mathrm{p})$ & $1.104(.302)$ & $-0.308(.766)$ & $0.482(.643)$ & $-1.337(.747)$ & $-1.414(.195)$ \\
\hline & \multirow{3}{*}{$\mathrm{BB}$} & PSG & $3.0 \pm 1.2$ & $2.8 \pm 1.5$ & $15.5 \pm 10.6$ & $15.0 \pm 10.0$ & $1.5 \pm 0.6$ \\
\hline & & OSG & $3.6 \pm 1.5$ & $6.4 \pm 5.7$ & $16.2 \pm 3.8$ & $17.2 \pm 4.1$ & $2.2 \pm 0.4$ \\
\hline & & $t(\mathrm{p})$ & $-0.651(.536)$ & $-1.235(.257)$ & $-0.139(893)$ & $-0.453(.664)$ & $-2.058(.079)$ \\
\hline \multirow{9}{*}{$\begin{array}{l}\text { Bow } \\
\text { arm }\end{array}$} & \multirow{3}{*}{$\mathrm{FE}$} & PSG & $12.6 \pm 10.3$ & $18.0 \pm 11.7$ & $45.6 \pm 28.8$ & $46.4 \pm 25.0$ & $4.0 \pm 1.6$ \\
\hline & & OSG & $13.6 \pm 7.8$ & $16.2 \pm 4.3$ & $36.6 \pm 13.4$ & $44.0 \pm 18.6$ & $3.8 \pm 1.5$ \\
\hline & & $t(p)$ & $-0.174(.867)$ & $0.324(.754)$ & $0.633(.544)$ & $0.172(.868)$ & $0.206(.842)$ \\
\hline & \multirow{3}{*}{ TB } & PSG & $5.2 \pm 4.8$ & $9.0 \pm 7.0$ & $48.4 \pm 25.3$ & $43.6 \pm 18.0$ & $2.6 \pm 1.5^{*}$ \\
\hline & & OSG & $6.4 \pm 2.1$ & $19.8 \pm 15.2$ & $69.2 \pm 20.5$ & $68.6 \pm 16.9$ & $5.6 \pm 1.7$ \\
\hline & & $t(\mathrm{p})$ & $-0.516(.620)$ & $-1.444(.187)$ & $-1.427(.191)$ & $-2.265(.053)$ & $-2.970(.018)$ \\
\hline & \multirow{3}{*}{ LS } & PSG & $6.6 \pm 2.3$ & $11.4 \pm 3.8$ & $32.2 \pm 8.1$ & $31.2 \pm 12.2$ & $5.0 \pm 1.9$ \\
\hline & & OSG & $10.0 \pm 2.4$ & $15.0 \pm 10.4$ & $29.6 \pm 16.7$ & $31.2 \pm 16.4$ & $8.4 \pm 4.5$ \\
\hline & & $t(\mathrm{p})$ & $-2.262(.054)$ & $-0.725(.489)$ & $0.314(.762)$ & $0.000(1.00)$ & $-1.558(.158)$ \\
\hline \multirow{6}{*}{ Trun } & \multirow{3}{*}{ RA } & PSG & $4.4 \pm 3.2$ & $5.2 \pm 3.7$ & $6.0 \pm 2.9$ & $5.8 \pm 3.1$ & $5.2 \pm 3.7$ \\
\hline & & OSG & $10.5 \pm 6.8$ & $12.3 \pm 7.4$ & $16.8 \pm 15.6$ & $12.0 \pm 4.9$ & $11.3 \pm 5.0$ \\
\hline & & $t(p)$ & $-1.792(.116)$ & $-1.877(.103)$ & $-1.529(.170)$ & $-2.323(.053)$ & $-2.096(.074)$ \\
\hline & \multirow{3}{*}{ ES } & PSG & $8.2 \pm 4.2$ & $11.0 \pm 8.9$ & $15.4 \pm 8.8$ & $16.6 \pm 11.2$ & $7.6 \pm 6.9$ \\
\hline & & OSG & $10.0 \pm 4.0$ & $15.3 \pm 6.3$ & $20.3 \pm 9.5$ & $21.8 \pm 8.3$ & $12.8 \pm 4.2$ \\
\hline & & $t(\mathrm{p})$ & $-0.651(.536)$ & $-0.802(.449)$ & $-0.794(.453)$ & $-0.760(.472)$ & $-1.309(.233)$ \\
\hline \multirow{3}{*}{ Leg } & \multirow{3}{*}{$\mathrm{RF}$} & PSG & $5.8 \pm 3.3$ & $9.4 \pm 3.8$ & $8.2 \pm 4.4$ & $7.4 \pm 3.1 *$ & $6.0 \pm 3.0$ \\
\hline & & OSG & $10.6 \pm 4.0$ & $11.6 \pm 4.6$ & $15.2 \pm 8.4$ & $14.0 \pm 3.5$ & $9.8 \pm 2.3$ \\
\hline & & $t(\mathrm{p})$ & $-2.085(.071)$ & $-0.819(.437)$ & $-1.646(.138)$ & $-3.125(.014)$ & $-2.255(.054)$ \\
\hline \multirow{3}{*}{ Glut } & \multirow{3}{*}{ GM } & PSG & $13.0 \pm 5.7$ & $14.2 \pm 6.8$ & $13.4 \pm 4.6$ & $13.0 \pm 5.1$ & $10.6 \pm 6.4$ \\
\hline & & OSG & $15.0 \pm 5.6$ & $17.0 \pm 10.9$ & $13.8 \pm 6.4$ & $14.0 \pm 6.3$ & $13.6 \pm 6.3$ \\
\hline & & $t(\mathrm{p})$ & $-0.559(.591)$ & $-0.486(.640)$ & $-0.113(.913)$ & $-0.278(.789)$ & $-0.745(.478)$ \\
\hline
\end{tabular}

Values are expressed as the mean \pm SD. Trun, Trunk; Glut, Gluteus; PD, Posterior deltoid; Tra, Trapezius; RM, Rhomboid major; LD, Latissimus dorsi; BB, Biceps brachii; FE, Forearm extensor bundle; TB, Triceps brachii; LS, Levator scapulae, RA, Rectus abdominis, ES, Erector spinae; RF, Rectus femoris; GM, Gluteus maximus, PSG, parallel stance group; OSG, oblique stance group; Ev(1), Junbi(Set); Ev(2), Geogung(Set up); Ev(3), Manjak(Full draw); Ev(4), Balsi(Release); Ev (5), Mamuri(Ending). *’:p<.05 significant difference between GSG and OSG. 
활성 변화를 비교했다. 깍지팔(Draw arm)의 등세모근 (Trap)의 Ev(1) 준비(Set)와 줌팔(Bow arm)의 위팔세갈래 근(TB)의 Ev(5) 마치기(Ending)에서 두 집단간의 차이가 나 타나, 사선 서기 집단(OSG)의 근활성이 높은 것으로 나타났 다(p<.05). 또한 넙다리곧은근(Rectus femoris, RF)의 $\mathrm{Ev}$ (4) 발시(Release)에도 사선 서기 집단(OSG)의 근활성이 높 은 것으로 나타났으며(p=.014), Ev(5) 마치기(Ending)까지 유지되는 경향을 나타냈다( $\mathrm{p}=.054)$.

\section{활의 장력과 팔, 다리, 몸통 근육의 근활성(EMGs)과의 상관관계}

〈Table 4〉에는 활의 장력과 활쏘기 동작의 Ev(3) 만작 (Full draw)과 Ev(4) 발시(Release) 시 각 근육의 근활성과 의 상관관계를 나타냈다. 활의 장력과 깍지팔(Draw arm) 의 위팔두갈래근(BB)의 $\mathrm{Ev}(4)$ 발시 시의 근활성과 유의한 상 관관계를 나타냈다(p<.05).

Table 4. The correlations between bowstring tension and muscle activity at event (3) and (4)(Ev(3), $\operatorname{Ev}(4)$ ).

\begin{tabular}{|c|c|c|c|}
\hline & & \multicolumn{2}{|c|}{ " muscle activity(\%MVC) } \\
\hline & & Ev(3) & Ev(4) \\
\hline \multirow{5}{*}{$\begin{array}{l}\text { Draw } \\
\text { arm }\end{array}$} & PD & .352 & .588 \\
\hline & Tra & -.242 & -.255 \\
\hline & $\mathrm{RM}$ & -.394 & -.489 \\
\hline & LD & -.196 & -.386 \\
\hline & $\mathrm{BB}$ & .301 & $.675^{*}$ \\
\hline \multirow{3}{*}{$\begin{array}{l}\text { Bow } \\
\text { arm }\end{array}$} & $\mathrm{FE}$ & .146 & .064 \\
\hline & ТВ & -.366 & -.413 \\
\hline & LS & .146 & .290 \\
\hline \multirow{2}{*}{ Trun } & RA & -.305 & -.334 \\
\hline & ES & .257 & .123 \\
\hline Leg & RF & -.379 & .004 \\
\hline Glut & GM & .023 & .046 \\
\hline \multicolumn{4}{|c|}{$\begin{array}{l}\text { Pearson's correlation coefficient was employed to determine the } \\
\text { relationship between parameters. Trun, Trunk; Glut, Gluteus; PD, } \\
\text { Posterior deltoid; Tra, Trapezius; RM, Rhomboid major; LD, Latissimus } \\
\text { dorsi; BB, Biceps brachii; FE, Forearm extensor bundle; TB, Triceps } \\
\text { brachii; LS, Levator scapulae, RA, Rectus abdominis, ES, Erector spinae; } \\
\text { RF, Rectus femoris; GM, Gluteus maximus, Ev(3), Manjak(Full draw); Ev } \\
\text { (4), Balsi(Release). *: p<0.05 between parameters. }\end{array}$} \\
\hline
\end{tabular}

\section{논 의}

본 연구는 우리나라 전통 활쏘기 동작에서 근육의 활성 정도를 평가하고자, 국궁에서는 처음으로 근전도(EMG)를 이용하여 깍지팔(Draw arm)과 줌팔(Bow arm), 몸통 (Trunk), 다리(Leg), 엉덩이(Gluteus) 근육의 활성도를 측정하였다. 상대적 비교를 위하여 각 근육의 최대수의적수 축(maximum voluntary contraction: MVC)을 기준값 으로 표준화(\%MVC)하여 비교하였다. 준비(Set)에서 마치 기(Ending)까지 5개의 상태(Event)로 나누어 평가한 결과, 깍지팔과 줌팔의 모든 근육에서 만작(Full draw)과 발시 (Release)에서 유의하게 증가하였다가, 마치기(Ending)에 유의하게 다시 감소하는 것을 발견하였다(Table 2), 활을 잡고 앞으로 미는 줌팔은 비주동팔(non-dominant arm) 이며, 시위를 잡고 당기는 깍지팔은 주동팔(dominant $\mathrm{arm})$ 이다. 즉 활을 잡고 미는 팔과 시위를 잡고 당기는 팔의 근육들이 만작과 발시 시에 활성화 되는 것을 의미한다. 한 가지 흥미로운 점은 그 활성 정도가 조금씩 다르다는 점이 다. 줌팔의 아래팔폄근무리(Forearm extensor bundle, $\mathrm{FE}$ )와 위팔세갈래근(Triceps brachii, TB), 깍지팔의 뒤어 깨세모근(Posterior deltoid, PD)과 등세모근(Trapezius, Trap), 큰마름근(Rhomboid major, RM)에서는 만작과 발시 시에 최대수축능력의 약 $41.1 \%$ 에서 $58.8 \%$ 까지 활성 되는 것으로 나타난 반면(p<.001), 줌팔의 어깨올림근 (Levator scapulae, LS)과 깍지팔의 넓은등근(Latissimus dorsi, LD), 위팔두갈래근(Biceps brachii, BB)에서는 약 $4.6 \%$ 에서 $31.2 \%$ 정도로 그 활성정도가 상대적으로 미약한 것으로 나타났다( $\mathrm{p}<.001)$.

아래팔폄근무리(FE)는 긴노쪽손목폄근(extensor carpi radialis longus), 짧은노쪽손목폄근(extensor radialis brevis) 및 자쪽손목폄근(extensor carpi ulnaris) 등으로 구성되어 주로 손목 폄 동작을 수행한다. 위팔세갈래근(TB) 은 주로 팔꿈치 폄 동작을 수행한다. 어깨올림근(LS)은 팔이 음뼈 이마면의 올림 동작을 수행한다. 즉 만작과 발시 시에 활을 잡고 앞으로 미는 팔은 팔꿈치와 손목을 펴는 동작을 위해 큰 힘을 발휘(최대 약 $41.1 \%$ 58.8\%)하지만, 팔이음 뼈 이마면의 올림 동작에서 발휘하는 근력은 상대적으로 미 약(30.9\% 31.2\%)하다고 판단된다.

활을 당기는 깍지팔의 경우에는, 뒤어깨세모근(PD)은 오 목위팔관절의 이마면의 벌림 동작과 가로면의 수평벌림(수 
평외전) 동작을 수행하고, 등세모근(Trap)은 팔이음뼈 가로 면의 모음과 위쪽 돌림 동작을, 큰마름근(RM)은 팔이음뼈 가로면의 모음과 이마면의 아래쪽 돌림 동작을 수행하는 근 육이다. 넓은등근(LD)은 오목위팔관절의 시상면의 폄 동작 과 이마면의 모음 동작을 수행한다. 위팔두갈래근(BB)은 팔 꿈치 굽힘 동작을 수행한다. 즉 만작과 발시 시에 시위를 잡 고 당기는 팔은 동작 중 오목위팔관절의 이마면의 벌림 동작 과 가로면의 수평벌림(수평외전) 동작, 팔이음뼈 가로면의 모음과 위쪽 돌림 동작을 위해 큰 힘을 발휘(최대 약 412.1\% 58.6\%)하지만, 오목위팔관절의 이마면의 벌림 동 작이나 팔꿈치 굽힘 동작에는 상대적으로 적은 힘을 발휘하 는 것(4.6\% 26.6\%)으로 판단되었다. 옛 중국의 사법서인 기효신서에서는 앞뒷손의 균형있는 밀고 당기기를 전수여 추태산 후수여악호미라 하였고(Min, 2010), 이의 영향인지 우리나라의 집궁제원칙에는 전추태산 후악호미라 하여 줌 팔은 태산을 미는 듯 강하게 밀고 깍지팔은 호랑이 꼬리를 잡듯 힘껏 당기라고 전하고 있다(Jung, 2013). 활쏘기 동작 시 줌팔과 깍지팔의 근육들이 각각 적절하게 작용하여 동작 을 만들어 내고 있다고 판단되었다. 최근 국궁 활쏘기 궁사 의 깍지팔과 줌팔의 어깨 굴·신 근력 및 어깨 외·내회전 근 력, 손목 굴·신근력을 비교한 연구에서 깍지팔의 근력이 유 의하게 높다는 보고되었다(Kim, 2020a). 이는 본 연구에서 깍지팔의 대부분의 근육들이 최대 약 $40 \%$ 이상 활성화 되는 것에서 그 이유를 찾을 수 있을 것이다. 또한 밀고 당기기 및 굳히기 국면에서 줌팔은 팔을 1 자로 펴져서 각 관절이 고정 되어 있는 상태로 유지되는 것과 대조적으로 깍지팔은 시위 를 뒤로 당기는 동작에서 팔꿈치를 굽히고 어깨를 수평회전 시키는 동작이 이루어져야 하기 때문에 상대적으로 위팔과 어깨의 근육이 크게 활성화 되는 것으로 판단된다. 국궁 궁 사들의 팔꿈치 및 어깨 관절의 등척성 최대 근력이 일반인들 에 비교하여 유의하게 높다고 보고되고 있어 이를 뒷받침하 고 있다(Kim, 2017). 또한, 국궁이 아닌 양궁의 경우이지 만, 경력 10 년 이상의 숙련된 양궁선수의 릴리즈(발시) 동작 을 고속 카메라를 이용하여 분석한 결과, 드로잉(만작) 후 릴 리즈 직전까지의 에이밍(굳히기) 동작 시 마치 동상처럼 움 직임이 없었다고 보고하고 있는 것처럼(Kim \& Kim, 2005), 밀고 당기기 및 굳히기 국면에서 신체의 정적 균형 을 유지하기 위한 양팔의 강한 힘이 중요하다는 것을 의미하 는 것이라 생각된다.

몸통(Trunk)에 있어서는 척주세움근(Erector spinae,
$\mathrm{ES})$ 은 줌팔과 깍지팔의 근육과 유사하게 만작과 발시 시 각 각 약 $17.6 \%$ 에서 $18.9 \%$ 까지 활성되는 것으로 나타난 반면, 배곧은근(Rectus abdominis, RA)에서는 근육이 활성화 되지 않는 것으로 나타났다. 척주세움근(Erector spinae, $\mathrm{ES}$ )은 몸통의 시상면에서 척추(허리) 폄 동작을 수행하고, 배곧은근(Rectus abdominis, RA)은 척추 굽힘 동작을 주 로 수행하는 근육이다. 활쏘기 동작 시 집궁제원칙에서는 흥허복실이라하여 가슴을 비우고 단전에 힘을 모으라고 전 하고 있으나(Jung, 2013), 실제 활쏘기 동작에서 단전에 힘 을 주고 있지 않는 것으로 나타났다. 척주세움근의 근 활성 은 단전에 힘을 주는 것 보다는 활과 화살을 밀고 당기는 동 작에서 허리는 곧게 세우고 자세를 유지하기 위해 활성화 되는 것으로 판단되었다. 넙다리곧은근(Rectus femoris, RF)과 큰볼기근(Gluteus maximus, GM)에 있어서는 근 활성의 유의미한 변화는 나타나지 않아, 활쏘기 동작 시 엉덩이와 하지의 근육 활성은 일정하게 유지되는 것으로 나타났다.

양궁에서는 활쏘기 동작 시의 근활성도를 비교한 연구들 이 보고되고 있다(Choi, 2020a; Choi, 2020b; Park \& Han 2019a; Park \& Han 2019b). 최근 여자 중학교 양궁 선수 한명의 $60 \mathrm{~m}$ 와 $30 \mathrm{~m}$ 슈팅 시 상지 주요근육과 척추기 립근의 근활성도를 비교 분석한 사례연구에서는 본 연구와 유사하게 드로잉, 백텐션, 슈팅, 슈팅 후 구간으로 나누고 국 궁의 깍지팔과 줌팔에 해당하는 당기는 팔(draw arm)과 미 는팔(bow arm)의 각각 4 개의 근육과 좌우 척주기립근 2 개 의 총 10 개 근육의 활성을 검토하였다(Choi, 2020a). 그 결 과 본 연구의 만작과 발시 시와 유사한 구간인 슈팅구간에서 의 근활성을 비교해 볼 때, 당기는 팔(깎지팔)의 위팔두갈래 근(BB), 뒤어깨세모근(PD)과 등세모근(Trap)과 미는 팔(줌 팔)의 위팔세갈래근(Triceps brachii, $\mathrm{TB}$ )은 각각 약 $37.4 \%, 27.1 \%, 20.6 \%, 35.7 \%$ 까지 증가하는 것으로 나타 나, 약 $16.2 \%, 42.1 \%, 55.4 \%, 56.1 \%$ 를 나타낸 본 연구와 약간의 차이가 있었다. 또한, 중고 여자 양궁선수9명을 대상 으로 슛 성공(최고점과 최저점 비교) 여부에 따른 상지주요 근육과 척추기립근의 근활성도를 비교한 연구에서도(Choi, 2020b) 유사하게 각각의 근육에서 약 $38.3 \%, 33.3 \%$, $32.9 \%, 28.6 \%$ 까지 증가하는 것으로 나타나, 이 역시 본 연 구와 약간의 차이가 있었다. 이는 활의 차이로부터 시작하 여, 장력, 성별, 연령 등 다양한 영향에 의하여 나타났을 것 으로 추측되어진다. 또한 이 연구 결과에서는 슈팅 구간 당 기는 팔(깎지팔)의 얕은손가락굽힘근(Flexor digitorum 
superficialis)과 미는 팔(줌팔)의 위팔세갈래근(TB), 등세 모근(Trap)에서 최저 점수일 때 최고 점수에 비해 더 높은 근활성을 나타내어 도리어 일부 근육에서의 강한 근수축은 정확성에 영향을 미칠 가능성도 시사하고 있다. 근육의 활 성도와 활쏘기의 정확성에 대해서는 추가적인 연구가 필요 할 것으로 사료된다.

한편, 마주서기 집단(PSG)과 사선서기 집단(OSG)의 활 쏘기 동작 시의 근활성을 비교한 결과, 사선서기 집단(OSG) 의 발시 상태에서 넙다리곧은근(RF)의 근활성이 마주서기 집단(PSG)에 비하여 높고, 마치기(Ending)까지 높게 유지 되는 것이 밝혀졌다(Table 3). 또한, 깍지팔의 등세모근 (Trap)의 준비(Set) 상태와 줌팔의 위팔세갈래근(TB)의 마 치기(Ending)에서 사선서기 집단(OSG)의 근활성이 높게 나타났다. 이러한 결과는 마주서기 와 사선서기의 차이는 활쏘기 동작 시 활을 들어 올리고, 밀고 당기고, 조준하는 동 작에서는 나타나지 않고, 활쏘기를 준비하고 마무리하는 자 세에서 일부 차이가 나타나는 것을 의미한다. 실제 활쏘기 동작에서의 만작과 발시 동작에서 깍지팔과 줌팔의 대부분 의 근육에서 근활성도가 최대치를 나타내는 반면, 넙다리곧 은근(RF)에서는 유의미한 변화가 없이 5.8 15.2\% MVC 내외의 수준을 유지하고 있었다. 이는 사선서기 집단(OSG) 이 발시 동작을 포함한 그 후 동작에서 하지를 버티기 위하 여 더 큰 힘을 발휘하고 있는 것을 의미한다. 또한 마주서기 집단(PSG)의 경우 조준을 위해서는 더 많이 상체를 회전시 켜야 하기 때문에 하지의 힘의 발휘가 상대적으로 제한되었 을 가능성도 있다. 준비 상태와 마치기에서의 두 집단의 차 이도 이러한 상체 회전으로 인해 힘이 분산되기 때문일 가능 성이 있다. 추후 활쏘기 동작 시의 신체 관절 각도 변화에 대 해 추가 연구가 필요한 이유이다.

활의 장력과 근활성(EMGs)과의 상관관계를 조사한 결과 에서는 깍지팔의 위팔두갈래근(BB)의 $\mathrm{Ev}$ (4) 발시 시의 근활 성과 유의한 정적 상관관계가 있는 것으로 나타났다 (p〈.05). 즉, 활의 장력이 높아질수록 발시 시에 깍지팔의 위팔두갈래근에 힘이 많이 들어가는 것으로 밝혀졌다. 이를 통하여 사용하는 활의 장력이 높을수록 깍지팔의 팔꿈치 굽 힘 근육인 위팔두갈래근의 근력을 더욱 높일 필요성이 있다 고 판단된다.

\section{결론 및 제언}

우리나라 전통 활쏘기 동작 시의 깍지팔(Draw arm)과 줌팔(Bow arm), 몸통(Trunk), 다리(Leg), 엉덩이 (Gluteus)의 근전도(EMG)를 측정하였다. 그 결과, 깍지팔 과 줌팔의 측정한 근육에서 만작(Full draw)과 발시 (Release)에서 유의하게 증가하였다가, 마치기(Ending)에 유의하게 다시 감소하는 것을 발견하였다. 몸통(Trunk)의 척주세움근은 만작과 발시 시 활성되는 것으로 나타난 반 면, 배곧은근과 넙다리곧은근, 큰볼기근에 있어서는 근 활 성의 유의미한 변화는 나타나지 않아, 활쏘기 동작 시 엉덩 이와 하지의 근육 활성은 일정하게 유지되는 것으로 나타났 다. 한편, 마주서기 집단(PSG)과 사선서기 집단(OSG)을 비 교한 결과, 발시 시 사선서기 집단의 넙다리곧은근의 근활 성이 마주서기 집단에 비하여 높고, 마치기까지 높게 유지 되는 것이 밝혀졌다. 또한, 활의 장력이 높아질수록 발시 시 에 깍지팔의 위팔두갈래근 근활성이 높아지는 것이 밝혀졌 다. 이러한 결과들로부터 국궁 활쏘기 시 복부 및 다리, 엉덩 이의 근육보다는 양팔과 등 근육의 활성을 높여 동작을 수행 하며, 마주 서기 자세일수록 상체를 비틀기 위하여 하지의 근활성을 억제 할 가능성과 활이 장력이 높을수록 깍지팔 위 팔두갈래근의 근력을 키워야할 가능성이 시사되었다.

\section{참고문헌}

An. H. S. (2018). Effects of Balance and Kinematic Factors on Archery Score during Archery Shooting. Journal of the Korea Convergence Society, 9(5),239-246.

Choi, D. S. (2020a). Comparison Analysis of Muscle Activity of The Upper Limb Muscles and Erector Spinae in Cadet National Athlete According to The Shooting Distance: Case Study. The Korea Journal of Sports Science, 29(2). 1149-1158.

Choi, D. S. (2020b). Comparison Analysis of Muscle Activity of The Upper Limb Muscles and Erector Spinae in Female Archery Players According to The Success and Failure of Shoot. The Korea Journal of Sports Science, 29(3). 899-908.

Ertan, H.(2008) Muscular activation patterns of the bow arm in recurve archery. Journal of Science and Medicine in Sport, 
12(3):357-60

Ertan, H., Kentel, B., Tumer, S. T. \& Korkusuz, F. (2003). Activation patterns in forearm muscles during archery shooting. Human Movement Science, 22. 37-45.

Jung. J. M. (2013). Hankookui Hwassogi. Seoul: Hakminsa(pp.280).

Kim, . T., \& Park, S. H. (2009). Effect of Scapular Stabilization Exercise on EMG Change of Shoulder Girdle and Trunk Muscle during Archer`s Shooting. Journal of Sport and Leisure Studies, 38(2), 1003-1010.

Kim, H.B., Kim, S.H. \& So, W.Y. (2015) The relative importance of performance factors in Korean archery. $J$ Strength Cond Res, 29(5):1211-1219. doi: 10.1519/JSC.0000 000000000687.

Kim, R. N., Lee, J. H., Hong, S. H., Jeon, J. H., \& Jeong, W. K. (2018). Clinics in Shoulder and Elbow, 21(3): 145-150. https://doi.org/10.5397/cise.2018.21.3.145

Kim. C. S. (2020a). The Relationships Among Body Weight Movement, Shooting Speed and Joint Muscle Strength During Archery Shooting Motion of Korean Traditional Archers. J. Korean Soc. Living Environ. Sys. Journal of Korean Society Living Environmental System, 27(4). 430-438.

Kim. C. S., Park. S. J., Kim. G. W., Kim. H. J. \& Kim. J. Y. (2017). Evaluation of muscle strength laterality in Korean traditional archers. Journal of Korean Society Living Environmental System. 24(3). 343-350.

Kim. J. H. \& Kim. H. Y. (2005). Kinematic Analysis on the Release Movement for Expert Archers. Korean Journal of Physical Eduaction, 44(4), 415-424.

Kim. J. H., Kim. K. C., \& An. H. S. (2015). Comparisons between Expert and Non-expert Players` Balance in Compound Bow of Archery. Sport Science, 33(1), 11-18.

Kim. J. P. (2000). The Correlation of the Physical Stability and the Performance of Archers in Non-shooting and Shooting. Korean Journal of Sports Biomechanics, 10(1), 133-147.

Kim. J. P. (2008). The Effect of Balance Exercise on Postural Control and Shooting Record in Archers. Korean Journal of Sports Biomechanics, 18(2), 65-74. DOI: 10.5103/KJSB.2008. 18.2.065.
Kim. T. H., \& Youm. C. H.(2013). Effects of Knee Joint Muscle Fatigue and Overweight on the Angular Displacement and Moment of the Lower Limb Joints during Landing. Korean journal of sport biomechanics, 23(1), 63-76.

Lee. S. Y., Seo. T. H., \& Jeong. Y. W. (2019). The Effects of Trunk Stabilization Training Emphasizing Transverse Abdominis Contraction on Static Balance and Game Records for Archers. PNF and Movement, 17(2);283-291. https://doi.org/10.21598/JKPNFA.2019.17.2.283

Leroyer, P., Hoecke, J., Helal, J. N. (1993). Biomechanical study of the final push-pull in archery. J Sports Sci, 11(1):63-69.

Manson. B. R., \& Pelgrim. P. P. (1986). Body stability and performance in archery. Exercise, (2), 88-101.

McGuine. T. (2006). Sports Injuries in High School Athletes: a Review of Injury-risk and Injury-prevention Research. Clinical journal of sport medicine, 16(6),488-499.

Min. K. G. (2010). Chosungwa Junggugui Gungsul. Seoul: Idam Books(pp.258).

Park, G. E. \& Han, T. K. (2019a). Analysis trunk muscle activity and standing balance ability of archery athletes. The Korean Journal of Physical Education, 58(3), 341-348, http://dx.doi.org/10.23949/kjpe.2019.05.58.3.23.

Park, G. E., \& Han, T. K. (2019b). Analysis of Muscle Activity during Shooting on Archers. The Korean Journal of Sport, 17(1). 905-914.

Seniam.(2006). Surface electromyography for the non-invasive assessment of muscles. Available at: http://www.seniam.org. Accessed 22 May.

Simsek, D \& Ertan, H. (2014). The different release techniques in high level archery: a comparative case study. Turkish Journal of Sport and Exercise, 16(3): 20-25. DOI: 10.15314/TJSE.201439609

Soylu, A. R., Ertan, H., \& Korkusuz, F. (2006). Archery performance level and repeatability of event-related EMG. Human Movement Science, 25, 767-774. 


\title{
국궁 활쏘기 동작 시 근활성 분석
}

\author{
김창선 ${ }^{1}$, Zhou YueZhu ${ }^{2}$, 박동호 $^{3}$, 김기훈 $^{4}$, 정왕수 $^{5}$, 김혜리 $^{5}$, 이기광 ${ }^{6}$, 민석기 $^{7}$ \\ 1동덕여자대학교 교수 \\ 2동덕여자대학교 대학원생 \\ 3 인하대학교 교수 \\ ${ }^{4}$ 육군사관학교 교수 \\ ${ }^{5}$ 국민대학교 대학원생 \\ ${ }^{6}$ 국민대학교 교수 \\ ${ }^{7}$ 한국스포츠정책과학원 책임연구위원
}

[목적] 양궁종목에서 근전도를 이용한 운동학적 연구는 증가했지만, 우리나라 전통 활쏘기인 국궁 관련 연 구는 전무한 실정이다. 본 연구의 목적은 국궁 궁사를 대상으로 활쏘기 동작중의 근전도를 평가하는 것이다. [방법] 대상자는 국궁 궁사 10 명으로 활쏘기 자세에 따라 마주 서기 그룹(PSG, n=5)과 사선 서기 그룹(OSG, $\mathrm{n}=5$ )의 두 집단으로 구분하였다. 근전도는 준비(Set), 거궁(Set up), 만작(Full draw), 발시(Release), 마치기 (Ending) 등 5개 동작의 활쏘기 국면에서 12 개의 근육에서 근전도를 측정했다. [결과] 만작 및 발시 시의 뒤어 깨세모근, 등세모근, 큰마름근, 깍지팔의 넓은등근, 위팔두갈래근, 아래팔폄근무리, 위팔세갈래근, 어깨올림근 의 근활성은 유의하게 증가하였다가, 마치기 국면에서는 다시 감소했다(p〈.01, p〈.001). 또한, 척주세움근의 근활성은 만작 및 발시 시 증가(p〈.01, p〈.001)한 반면, 배곧은근, 넓다리곧은근, 큰볼기근에 있어서는 유의한 변화는 없었다. 마주 서기 집단과 사선 서기 집단을 비교한 결과, 사선 서기 집단의 넓다리곧은근 근활성은 마주 서기 집단의 발시(p<.05) 국면 보다 높았고, 마치기 국면까지 유지되었다(p<.05). 한편, 활의 장력이 높아 질수록 발시 시에 깍지 팔의 위팔두갈래근 근활성이 높아졌다(p<.05). [결론] 국궁 활쏘기 시 복부, 다리, 엉덩이 근육보다 양팔과 등 근육이 더 활성화된다는 것이 시사되었다. 또한, 마주 서기 자세시에 상체를 비틀기 위해 하지의 근활성이 억제될 가능성이 있으며, 활의 장력이 높을수록 깍지 팔의 위팔두갈래근 근력 증가가 필요할 것으로 판단된다.

주요어: 국궁, 활쏘기, 근육, 근전도, 발시 